\title{
Estimating Clinical Burden and Valuation of Weight Management Strategies (using Willingness to Pay - WTP) for Overweight and Obesity in Primary Care Setting in Borneo Sarawak, Malaysia
}

\section{Zafar Ahmed}

Universiti Malaysia Sarawak

Euphrasia Anak Bari

Universiti Malaysia Sarawak

Noormah Z Ahmed

Dow International Medical College

Sharifa Ezat Wan Puteh ( $\nabla$ shaezat@gmail.com )

Universiti Kebangsaan Malaysia Fakulti Perubatan

\section{Research}

Keywords: Overweight \& obesity, Willingness to Pay (WTP), Contingent Valuation Method (CVM), Burden of Disease (BoD), Sarawak Malaysia

Posted Date: July 14th, 2020

DOI: https://doi.org/10.21203/rs.3.rs-36178/v1

License: (9) This work is licensed under a Creative Commons Attribution 4.0 International License.

Read Full License 


\section{Abstract \\ Background}

Overweight and obesity is one of the most serious public health challenges of the 21 st century. Despite the consequences of obesity, participation in weight management programs. Aim of this study is to estimate the clinical burden of obese patients in government primary care clinics in Kuching, Sarawak. We use randomized patients from these clinics to carry out a willingness to pay study for weight management and estimated the economic burden of overweight and obesity management in primary care setting in Sarawak. Identifying their willingness to pay will help in formulation and implementation of policies for effective weight management therefore improve the quality of care in future. Clinic based cross-sectional study involving 252 randomly overweight and obese patients (with $\mathrm{BMI} \geq 23$ ), age 18 to 59 years old, who attended outpatient department.

\section{Results}

Patients indicated their preference for three hypothetical weight reduction programs: diet, exercise, drug and combination of all. Data from secondary sources was used to estimate the prevalence of overweight and obesity in Sarawak. Out of 1,504,779 patients aged 18 to 59 years attending government health clinics in Sarawak, it was estimated that overweight and obesity would account for approximately $30 \%$ of total adult patients (451,433 patients). Conversion to USD was based on December 2015 conversion rate of USD 100 to MYR 430.31. The median willingness to pay was MYR 44.87 (USD 11.56), MYR 88.80 (USD 21.01), and MYR 60.18 (USD14.24) for Drug and Exercise, Diet and Exercise and Drug, Diet and Exercise respectively.

\section{Conclusion}

Resource allocation for weight management intervention in Sarawak, Malaysia depend on evaluation of weight management intervention (objectively measured by WTP) and the availability of fixed budget from State Health Department. The total WTP for weight reduction intervention via diet and exercise was MYR 22, 512, 963.71 (USD 5,231,801.19), while weight reduction intervention via drug, diet and exercise was MYR of 40, 087, 250.40 (USD 9,315,900.30) and weight reduction intervention via drug and exercise was MYR 27, 167, 237.94 (USD 6,313,410.78). Clinical and economic burden of overweight and obesity in Sarawak is substantial. Therefore implementation of effective policies and programs are essential in tackling obesity.

\section{Background}

Obesity is a global problem in both developing and developed countries, and has become a leading health burden in the Non-Communicable Diseases (NCD) such as cardiovascular and diabetes $[1,2]$. 
Overweight and obesity is one of the most serious public health challenges of the 21 st century, and constitute a threat worldwide fall the way from early age to adolescence and to the adulthood $[3,4]$. In between the accelerated phase of industrialisation and urbanisation in recent decades, the worldwide prevalence of obesity has more than doubled between 1980 and 2014.

Obesity is defined as an abnormal or excessive accumulation of body fat and it is currently one of the most concerning public health issues, as it is related to a wide range of serious diseases and disorders [5]. Furthermore, obesity has reached epidemic proportions globally, with more than 1 billion adults overweight - at least 300 million of them clinically obese - and is a major contributor to the global burden of chronic disease and disability [6]. In addition, there is a high prevalence of obesity in the general population, making it the principal nutritional problem in the developed world today [7].

In 2014, more than 1.9 billion adults of age 18 years and older, were overweight and of these over 600 million were obese. Overall, about $13 \%$ of the world's adult population, $11 \%$ of men and $15 \%$ of women were obese whereas $39 \%$ of adults aged 18 years and over were overweight, comprising of $38 \%$ of men and 40\% of women ${ }^{8}$. From GutieÂrrez-Fisac et al. reported, between 1987 and 1995/1997 the prevalence of overweight and obesity in the Spanish adult population aged 25-64 y increased by $2.2 \%$ and $3.9 \%$, respectively. This increase was seen in both men and women and affected most age groups [7]. According to Kelly et al., they were predicted that by 2030 , about 573 million and 1.35 billion adults would have problems with obesity and overweight, respectively [9].

Obesity and overweight have been steadily increasing in ASEAN countries over the last three decades, not just in higher income countries but also in low-and middle-income nations and obesity has become a leading health issue Malaysia is no exception when increased rapidly $[10,11]$. Where Malaysia is also facing a big challenge in combating this rising obesity epidemic although there is increasing availability and accessibility to health screenings. By comparison, 20 years ago, only $4 \%$ of Malaysians were considered obese [10]. Nowadays, Malaysia is reported to have the highest obesity rate in Southeast Asia [12]. Using World Health Organization recommendations for body mass index (BMI), the prevalence of overweight and obesity in Malaysia was found to be $33.6 \%$ and $19.5 \%$ respectively [13]. The National Health and Morbidity Surveys (NHMSs) carried out in 2006, 2011 and 2015 showed further increase in the prevalence of overweight and obesity among adults $\geq 18$ years from $29.1 \%$ and $14.5 \%$ in 2006 , to $29.4 \%$ and $15.1 \%$ in 2011 to $30.0 \%$ and $17.7 \%$ in 2015 respectively, and there were 5.6 million Malaysian who were pre obese and 3.3 million are obese $[14,15,16]$. For 2019, NHMSs reported, 1 in 2 adults in Malaysia were overweight or obese. This was found to be highest among: females $54.7 \%$; Indian ethnicity $63.9 \%$ and $55-59$ years old age group $60.9 \%$ [17].

Overweight and obesity is a complex disorder involving not only a cosmetic concern but it also increases the risk of other medical condition such as heart disease, diabetes and high blood pressure [18]. Prevalence of obesity in any population have far reaching effect on the health of the population. These include increased premature mortality, morbidities associated with many chronic disorders associated 
with the obesity, and reduced health related quality of life. All these will lead to the substantial increase in budgets of various segments of health systems [19].

In a systematic review of the economic burden of obesity worldwide, Withrow and colleagues concluded that obesity accounted for $0 \cdot 7-2 \cdot 8 \%$ of a country's total health-care costs, and that obese individuals had medical costs $30 \%$ higher than those with normal weight [20]. Obesity imposes significant costs on health-care systems; around the world, 2 to 7 percent of all health-care spending relates to measures to prevent and treat this condition, with up to 20 percent of all health-care spending attributable to obesity, through related diseases such as type 2 diabetes and heart disease [21]. Obesity reduces productivity significantly and has a direct impact on the country's GDP performance [22]. This can be prove, in 2008 the economic cost of obesity in Canada was estimated at $\$ 4.6$ billion, up about $19 \%$ from $\$ 3.9$ billion in 2000 [23]. These health-care costs place a burden on government finances. Furthermore, overall economic productivity and employers are both affected by impaired productivity [21]. Malaysia also suffers the highest overall cost for obesity as a percentage of the country's healthcare spending, reaching an alarming $10-20 \%$ of the country's healthcare expenditure [22]. Malaysia's total cost for obesity as a percentage of nominal GDP ranks top at a range between $0.4 \%$ and $0.8 \%$, far ahead of all other countries in ASEAN [23]. Total (direct and indirect) costs of obesity are highest in Malaysia, are equivalent to between $10 \%$ and $19 \%$ of national healthcare spending. Indonesia's costs range from $8-16 \%$ of national healthcare spending. Costs are lowest in Vietnam (1-3\% of national healthcare spending) and Thailand $(3-6 \%)[10]$.

Despite the grave consequences of overweight and obesity and its long term treatment, the participation in weight reduction management in primary health care is notoriously poor. Patients are less likely than the providers to look to the primary care clinic as a resource for weight management, as they perceived that overweight people should handle their weight on their own and that consultation with a health care provider would not be helpful. Therefore it is essential for health care providers to be aware that their patients are less likely to seek their providers for assistance and thus delivering of consultation on weight management must be initiated by the provider [24].

\section{Willingness to Pay - WTP}

The potential benefits of interventions for weight reduction are substantial. The health benefit has been widely assessed based on the concept of willingness to pay (WTP) which is based on the principles of welfare economic theory and cost benefit analysis. Conferring to the theory of welfare economics, the maximum amount that the individual is willing to pay for such a service or intervention defined the benefit to an individual of a service or an intervention and the sum of each individual's WTP can be regarded as the benefit to society of the intervention [24].

Among the several methods used for measuring WTP, the contingent valuation (CV) is a comprehensive approach providing a theoretically precise and complete measure of WTP. The contingent valuation (CV) method is a well-known research approach which uses survey techniques to elicit patient's valuation of 
non-market goods including health [25]. CVM is a nonmarket-valuation method that is used to value specific changes from the status quo.

CVM is a stated-preference technique, as in the individual "states" his preference. Specifically, in the CVM individuals are asked about the status quo versus some alternative state of the world, and information is elicited about how the individual "feels" about the alternative relative to the status quo, and their WTP, if anything, for the alternative. Before the CVM question is asked, individuals are presented with background and explanatory material, and often asked other questions.

A higher WTP may indicate a more number of participation if such a program were offered and the WTP also indicate whether a sponsor organization can recover some or all of the intervention costs from program participants based on the participants willingness to pay. If at-risk individuals are willing to pay a significant portion of the costs of an intervention, then it may be practicable for sponsors to implement interventions without suffering large financial burdens. However it is important to take into account that the benefit of such non-market goods (health) may also be subjected to an individual's health and economic condition [25].

Valuation is implicit in most policy decisions, and it is preferable to make it explicit where possible to improve quality and transparency. For that reason the CV method is adopted in this study and a survey is conducted among the overweight and obese patients on their WTP for health improvement secondary to weight reduction management.

\section{Primary Health Care in Malaysia}

Malaysia state healthcare system has been heavily financed through the government tax based financing, although its health care prosper under bipartite public and private providers. Under the universal health coverage, Malaysia's public out patients healthcare is provided almost fee exempted and nominal payment upon admission as inpatient. Employer-based financing covers a limited number of companies and private insurance, that engage private health providers, mostly are concentrated in urban areas. Primary care facilities in Malaysia are highly subsidized by the government under the universal coverage, leading to very low state cost recovery. Malaysian citizens have to pay a user fee of only MYR1 (estimated to be USD 0.38) for each primary care outpatients' payment. [26]

\section{Primary Health Care Services in Sarawak}

Sarawak is the largest state in Malaysia with an area of 124,450 square kilometres and a population of almost 2.8 million in 2018, making it the fourth most populous state yet with the lowest population density in Malaysia at only 20 people per square kilometre [27]. Sarawak is challenged with difficult terrain as $80 \%$ of its land is covered with forest (Forest Department Sarawak, 2012) [28]. Many components of Sarawak's healthcare services were designed specifically to fit its context, especially in terms of delivery of Primary Health Care (PHC) services. 
In the early days of Sarawak, the first clinic was initiated by missionaries in the early 1900s. Then in the 1940s, clinics were established in rural areas by the Sarawak Medical Department and were called as Dispensaries back then. These Dispensaries were led by 'dressers' or Hospital Assistants (HA) and provided both basic outpatient care and limited in-patient care. Realising that many patients in remote areas faced obstacles in seeking treatment at these clinics due to transport difficulties, the colonial government introduced mobile health services (Travelling Dispensaries) in 1948 which mainly benefitted settlements along major riverbanks. Then, in the 1960s, static and travelling dispensaries and $\mathrm{MCH}$ clinics were integrated and expanded through Rural Curative Services (RCS). Following the formation of Malaysia in 1963, the Medical Department became a federal agency and all health services and facilities were put under the jurisdiction of the $\mathrm{MOH}$ and the Sarawak Medical Department. Major changes to these clinics took place in the 1970s where clinics were upgraded to Klinik Desa (KD, village clinic) when the KD management concept was implemented in 1979 (Sarawak State Health Department, 2012) [29]. The KD Management System was conceived by Dr Stalin Hardin who was the Acting State Medical Director of Sarawak at that point of time. The system designed KDs as a one-stop health centre which provided more comprehensive services than Static Dispensaries encompassing outpatient care, $\mathrm{MCH}$ care, environmental sanitation, and follow-ups for chronic illnesses. This concept attracted the interest of many, and the system was adopted and implemented nationally in Malaysia. Since then, clinics' infrastructure and facilities and the implementation of healthcare services in Sarawak became parallel with the national PHC component in the Family Health Development programme.

For almost half a century, the core concept of KD Management remained in place in Sarawak. Each clinic was designed to serve a population of between 1,500 and 3,000 people living within a radius of $12 \mathrm{~km}$ from the clinic. The operational area of each clinic is divided into an immediate area which is within $5 \mathrm{~km}$ radius of the clinic and an extended area which lies between $5 \mathrm{~km}$ to $12 \mathrm{~km}$ radius of the clinic.

Communities living within the immediate area are expected to come and obtain healthcare at the nearby clinic, while those living within the extended area are visited by the mobile health team monthly via land and water [30]. Those living outside the clinics' operational areas are reached by Flying Doctor Services (FDS) which was introduced in 1973 in Sarawak. FDS provides monthly basic healthcare services using a helicopter with a team consisting of a medical officer, an assistant medical officer and two community nurses [31].

To date, public PHC services in Sarawak generally are delivered through two different modes which are static and mobile health services. Static services are delivered through four main public primary care facilities - 1) health clinics (Klinik Kesihatan, KK), 2) community clinics (Klinik Komuniti, KKOM) which were previously known as 1 Malaysia Clinics, 3) village clinics (Klinik Desa, KD) and 4) maternal and child health clinics (Klinik Kesihatan Ibu dan Anak, KKIA). As of 2018, there were a total of 275 government primary care facilities that provide static PHC services in Sarawak; $210 \mathrm{KK}, 24 \mathrm{KKIA}, 36 \mathrm{KKOM}$ and 5 KD [32]. These different types of facilities may have similarities and differences in terms of service coverage, human resources and geographical context. 
KKs are mostly available throughout the state and serve both the rural and urban populations. To manage the operation and resource allocation of these PHC facilities, KKs are classified either based on daily patient attendance at these facilities or the floor plan or infrastructure of these facilities. Clinic classification according to infrastructure is made based on the catchment population for these facilities and thereon, the types of services provided. PHC services provided in KKs have a wide range of scope ranging from promotive, preventive, curative to rehabilitative care. KK Type 1-3 (infrastructure type) are typically large clinics, serve large populations (more than 30,000 populations) in the urban areas and provide an advanced level of services. It can be co-located or combined with KKIA, dental clinics or could be in district hospitals. These KKs have a full range of health personnel - Family Medicine Specialist (FMS), Medical Officers (MO) and paramedics, Assistant Medical Officers (AMO), and nurses (Matron, Sister, Staff Nurses and Community Nurse). Other disciplines with specialised care which include physiotherapy, occupational therapy, nutrition, diet, and high technological support services - laboratory, diagnostic imaging, and pharmacy are also made available. Services at advanced levels may also receive referrals from smaller clinics which provide either universal or intermediate level services.

KKs with infrastructure Type $4-6$ are smaller clinics (5,000 to 30,000 populations) mostly located in rural and remote areas. These clinics may provide intermediate or universal service. Intermediate services are provided by paramedics and medical officers without specialist care. Services are delivered at the universal level by paramedics (either by Assistant Medical Officer or Community / Registered Nurses, or both). Type $7 \mathrm{KK}$ was recently added and represents the smallest KK (less than 5,000 populations). Some Type 7 KKs are such as upgraded Village Clinics (Klinik Desa) mandated with an expanded scope. In general, Types 6 \& 7 KKs provide universal services, Types 4 and 5 provide intermediate services, and Types 1, 2 and 3 implement advanced primary care services [33].

KDs (Klinik Desa, Village Clinic) mainly serve rural populations, provide $\mathrm{MCH}$ services and basic curative services, and are led by Staff Nurses or Community Nurses. KKIA (Klinik Kesihatan Ibu dan Anak, Maternal and Child Health Clinic), located in both urban and rural areas. These facilities provide only $\mathrm{MCH}$ services which include family planning program. KKIAs are manned by Medical Officers and midwives with or without nurses. Some KKIAs are combined with KKs in terms of facilities.

Mobile health services significantly contribute to the health of the population in Sarawak. Mean distance of public outpatient clinics in Sarawak was $11.48 \mathrm{~km}$ and travel time of 30 minutes [34]. However, distance and travel time taken could be longer in more remote areas. Therefore, mobile services were established to provide basic healthcare services to populations living outside the clinics' operational area which require access using boat, 4WD or helicopter. These mobile health services provide $\mathrm{MCH}$ services and basic curative services. And each mobile team consist of AMO, with or without nurses or may include MO. In 2016, there were 132 mobile health teams in Sarawak: 66 for land transport, 57 for water transport and 9 for air transport.

In addition to the existing health facilities, the 1Malaysia Clinic (1M Clinic) was introduced in 2010, including the mobile 1Malaysia Bus Clinic and 1Malaysia Boat Clinic [35]. There is no $1 \mathrm{M}$ Bus Clinic in 
Sarawak. Static $1 \mathrm{M}$ Clinics are in urban areas and mainly serve the urban poor population, whilst the 1 Malaysia mobile teams serve remote rural populations. The $1 \mathrm{M}$ Clinics provide basic curative services and are usually led by an AMO with or without nurses. Later, the $1 \mathrm{M}$ Clinics received MOs as additional staff. Previously in Sarawak, there were two $1 \mathrm{M}$ Boat Clinics serving the remote populations along the Upper Rejang River in Kapit Division and Baram River in Miri Division. However, currently only $1 \mathrm{M}$ Boat Clinic in Baram River still in operation[36]. In 2018 following Malaysia's 14 ${ }^{\text {th }}$ General Election and as a result of the change in the federal government, the name $1 \mathrm{M}$ Clinic was rebranded into Community Clinic (Klinik Komuniti). Then, some of the $1 \mathrm{M}$ Clinic premises and operations were upgraded into KK, while $1 \mathrm{M}$ Clinics with less than 50 patients daily were closed [37].

No study has been reported, especially in the local Malaysian setting to have attempted to estimate the Willingness to Pay (WTP) for weight management in primary care (from patients' perspective). This study aims to estimate the Willingness to Pay (WTP) for weight management in primary care clinic in state of Sarawak, Malaysia. This will help put the weight management strategies in the right policy perspective and can assist in the successful implementation of such policies. This in turn can help to improve and ensure a better quality of care for the obese patients at the primary health clinics and better direction in the implementation of policies in the future.

\section{Methodology}

A cross-sectional study carried out at all the five government health clinics (with Family Medicine Specialist) in Kuching District, Sarawak Malaysia. Total of 400 overweight and obese patients (with BMI of $\geq 23$ ), age 18 to 59 years old who attended outpatient department were selected with systematic random sampling for a face to face structured questionnaire. The questionnaire was adapted from Fu et al. (2011) ${ }^{25}$. Approval for this study was obtained from the Ethical Committee of Faculty Medicine and Health Science, Universiti Malaysia Sarawak and Clinical Research Centre Malaysia, Ministry of Health.

During the interview, the respondent was first asked if he/she wanted to reduce weight. Those who responded positively were then asked follow-up questions. The participants were given explanations on the economic term used in the questionnaire to ensure complete understanding of the situation. Three hypothetical situations were clarified to the respondents and they were expected to vote the amount of money they willing to pay if they are in the situation in three different weight reduction methods. These include; drug and exercise, diet with exercises and combinations of all three (Table:1). There were 7 offer prices use in the questionnaire ranging from MYR 50 (USD 11.83) to MYR 500 (USD 118.33) . 
Table 1

Hypothetical Scenarios for Willingness to Pay (WTP):

\section{Scenario Scenario Description}

Scenario 1 Reduce weight by $5 \mathrm{~kg}$ in 3 months with drug and exercise

Scenario 2 Reduce weight by $5 \mathrm{~kg}$ in 3 months with diet and exercises

Scenario 3 Reduce weight by $5 \mathrm{~kg}$ in 3 months with drug, diet and exercise

If they agreed to pay, then the bidding process commenced. The answers were close ended with two options ('yes' and 'no'). However, if the respondents answered 'no' they were asked about the reason and the interview stop there. The bidding started with the lowest value depend on the pre-test and subsequently higher and stop once the respondents state they were unwilling to pay the given amount. If the respondents said no or yes to the entire bidding, open ended question was asked about what the highest amount that they were willing to pay.

\section{Results}

From the total 400 patients interviewed, $63 \%(n=252)$ of the overweight and obese patients were willing to reduce their weight and 37\% were unwilling to reduce their weight. Table 2 shows preference for each scenario and the amount these patients are willing to pay for each scenario.

Table 2

Preference for each scenario and the Median WTP for each scenario

\begin{tabular}{|lll|}
\hline Scenario & Preference (\%) & Median WTP (MYR) \\
\hline Scenario 1: Drug and Exercise & 71.8 & 48.87 (USD 11.56) \\
\hline Scenario 2: Diet and Exercises & 94.1 & 88.80 (USD 21.01) \\
\hline Scenario 3: Drug, Diet and Exercise & 70.6 & 60.18 (USD14.24) \\
\hline
\end{tabular}

*USD base on exchange rate for December 2015 (USD 1 = MYR 4.3031)

The preferred scenario was the scenario 2 (Diet and Exercises) among the three scenarios offered.

Clinical burden of the overweight \& obese patients is estimated using the screening data collected routinely by each primary care clinic, and is estimated 30\% throughout the year 2014 and 2015 at all primary care clinics in Sarawak. The total number of overweight and obese patients in state of Sarawak, Malaysia was estimated at 451, 433. This should be regarded as the "Burden of Overweight and Obese patients" at the primary care clinics in the state of Sarawak, Malaysia. The estimation at the different division level is shown in the Table 3. 
Table 3

Distribution of estimated overweight and obese adult patients in each Division in Sarawak, Year 2015

\begin{tabular}{|c|c|c|}
\hline Division & Total adult patients' attendance & $\begin{array}{l}\text { *Estimated overweight } \\
\text { \& obese adult patients }\end{array}$ \\
\hline Kuching & 418,041 & 125,412 \\
\hline Samarahan & 198,980 & 59,694 \\
\hline Sri Aman & 170,471 & 51,141 \\
\hline Betong & 132,817 & 39,845 \\
\hline Sarikei & 68,997 & 20,699 \\
\hline Sibu & 100,559 & 30,167 \\
\hline Kapit & 21,987 & 6,596 \\
\hline Mukah & 18,752 & 5,625 \\
\hline Bintulu & 176,232 & 52,869 \\
\hline Miri & 104,697 & 31,409 \\
\hline Limbang & 93,246 & 27,973 \\
\hline Total & $1,504,779$ & 451,433 \\
\hline
\end{tabular}

With the value obtained from Table 2 and Table 3, estimation of the total amount of WTP among overweight and obese adult patient population in government health clinics in Kuching District and whole Sarawak were calculated for the three scenarios. The results are shown in the Table 4.

Table 4

Total amount of WTP among overweight and obese individuals for patient population in government health clinics in Sarawak (estimated $n=451,433$ ).

\begin{tabular}{|lll|}
\hline Scenario & Median WTP (MYR) & Total WTP (MYR) \\
\hline Scenario 1: Drug and Exercise & 48.87 (USD 11.57) & 22, 512, 963.71 (USD 5,231,801.19) \\
\hline Scenario 2: Diet and Exercises & 88.80 (USD 21.01) & $40,087,250.40$ (USD 9,315,900.30) \\
\hline Scenario 3: Drug, Diet and Exercise & 60.18 (USD 14.24) & $27,167,237.94$ (USD 6,313,410.78) \\
\hline
\end{tabular}

*USD base on exchange rate for December 2015 (USD 1 = MYR 4.3031) 
Table 4 illustrated the total amount of WTP in overweight and obese patient population in Sarawak for each scenario. The highest total amount of WTP among overweight and obese adult patients in government health clinic in Sarawak was in Scenario 2 (weight management intervention via diet and exercise) with the MYR 40, 087, 250.40 (USD 9,315,900.30) followed by Scenario 3 (weight management intervention via drug, diet and exercise) with the MYR of 27, 167, 237.94 (USD 6,313,410.78). Scenario 1 (weight management intervention via drug and exercise) had the lowest total amount of WTP, MYR 22, $512,963.71$ (USD 5,231,801.19).

\section{Discussion}

As the data revealed that $30 \%$ of the adult patient population were estimated to be overweight and obese in a patient population of 200, 577 persons aged 18 to 59 years in Kuching District, it was estimated that overweight and obesity would account for approximately 60,173 cases, in the Year 2015. While in a patient population of 1, 504, 779 persons aged 18 to 59 years in Sarawak, it was estimated that overweight and obesity would account for approximately 451, 433 cases in the Year 2015. Comparatively, the prevalence of overweight and obesity among the patient population in Sarawak was similar to the general population in Malaysia, in which the overweight and obese were about one third of the general population [38].

This indicates that overweight and obesity are the major clinical burden of disease, not only affecting people across the globe but also in Malaysia itself. Overweight and obesity are the root cause for various non-communicable diseases and often affect the quality of life, productivity and may lead to disability. As the medical cost of managing weight-related chronic diseases increased, it further raises the financial burdens of our health care system and also will contribute toward additional financial burdens being placed on public health insurance $[39,40]$. Economic evaluation assesses the efficiency and allocation of resources to interventions that may improve health care and health outcomes [41].

Therefore, comprehension of the potential morbidity and cost implications is crucial to formulate an effective and cost-effective strategy for weight management. The economic rationale in the study warrants that there should be cost-effectiveness across a spectrum of different weight management interventions in overweight and obesity patients. For that purpose we employed the Willingness to Pay (WTP) based Contingent Valuation Technique (CVM) in this research.

However, in a publicly funded health care system such as in Malaysia, resources are usually scarce with fixed amount of resources per annum. If there is a need to carry out changes in the services based on demand and needs of the population, policy makers may have to decide on which services or programs that need to be expand or withhold, within the context of a fixed budget allocated, as according to the concept of economic evaluation [42]. Economic evaluation is the process of measuring cost effectiveness which is the cheapest option is a simplistic and mistaken idea [43].

Efficiency and its effectiveness in developing strategies for weight management states that all the costs associated with obesity management should be equal or below the WTP for weight management 
intervention. Hence to translate this information into formulation of strategies for weight management intervention, the cost for weight management intervention via various strategies i.e.; diet and exercise; drug, diet, exercise; drug and exercise in state of Sarawak, Malaysia should be equal or less than the amount of WTP. Therefore in Sarawak should be equal or less than the amount of WTP, MYR 40.0 million (USD 9,295,624.08), MYR of 27.1 million (USD 6,297,785.31) and MYR 22.5 million (USD 5,228,788.54) for three strategies respectively.

To assist policy makers in decision making, the value of health benefits from the program should be greater than the "opportunity cost" of other programs that are being considered. For instance, weight management intervention via diet and exercise; via drug, diet, exercise; via drug and exercise in Sarawak which were valued as MYR 40.0 million (USD 9,295,624.08), MYR of 27.1 million (USD 6,297,785.31) and MYR 22.5 million (USD 5,228,788.54) respectively from the WTP measurement, can be adopted if these values are greater than the opportunity costs of other competing programs or services available under Ministry of Health. In addition to that, other than valuation of benefits and barriers for weight management, policy makers may also need to assess other related aspects such as feasibility, budget, cultural concern, time, equity before any decision is made ${ }^{5}$.

\section{Conclusion}

Resource allocation for weight management intervention in primary care in the State of Sarawak, Malaysia may depend on several factors such as the evaluation of weight management intervention (objectively measured by the concept of WTP) and the available fixed budget from State Health Department. From the findings in our study, preferably cost of the weight management program should be equal or less than MYR 40.0 million (USD 9,295,624.08), MYR of 27.1 million (USD 6,297,785.31) and MYR 22.5 million (USD 5,228,788.54) respectively from the WTP measurement for weight management intervention via drug and exercise; via diet and exercise; via drug, diet and exercise respectively.

\section{Declarations}

\section{Ethical Approval and Consent to participate}

Approval for this study was obtained from the Ethical Committee of Faculty Medicine and Health Science, University Malaysia Sarawak and Clinical Research Centre Malaysia, Ministry of Health. All the participating patients were first briefed by the researcher assistant and if the patients agreed to be part of the study, a written consent was obtained.

\section{Consent for publication}

Not applicable

\section{Availability of supporting data}


The datasets used and/or analysed during the current study are available from the corresponding author on reasonable request.

\section{Competing interests}

The Authors declare that there is no conflict of interest during the time of conception and conduct of the study.

\section{Funding}

Entire research was self funded, and no external funds are used during the conceptualization, development of the proposal, conducted of the research, data collection and analysis, and writing and submission of the manuscript

\section{Authors' contributions}

Zafar Ahmed. Conceptualize the research and developed the proposal, conducted the research, data collection and analysis, and contributed writing the manuscript

Euphrasia Bari. Conceptualize the research and developed the proposal, conducted the research, data collection and analysis, and contributed writing the manuscript

Noormah Z. A. Data analysis, and contributed writing the manuscript

Sharifa Ezat Wan Puteh. Conceptualize the research Data analysis, and contributed manuscript writing, editing and submission.

All authors read and approved the final manuscript.

\section{Acknowledgements}

The authors would like to express their gratitude to everyone who have helped us conceptualize and conduct this study. Special thanks to the department of community Medicine and Public Health at the University Malaysia Sarawak (UNIMAS) and the Ministry of Health Malaysia and Sarawak State Health Department. We are also immensely grateful to everyone for their comments on an earlier version of the manuscript, although any errors are our own and should not tarnish the reputations of these esteemed persons

\section{References}

1. Mahaletchumy A, Rampal L, Sharif ZM. Prevalence of overweight/obesity and its associated factors among secondary school students in semi urban area in Malaysia. Med J Malaysia. 2019;74:51320. 
2. Mohamad Nor, Ambak N, Mohd Zaki RN, et al. An update on obesity research pattern among adults in Malaysia: a scoping review. BMC Women's Health. 2018;18:1-15.

3. Kusnanto H. Catastrophic failures of public health. Lancet. 2004;363:745.

4. World Health Organization. Global strategy on diet, physical activity and health. http://www.who.int/dietphysicalactivity/publications/facts/obesity/en/. Accessed 30 May 2020.

5. Morais Macieira LM, Tavares L, de Andrade Saraiva JM, da Conceição Santos L. Overweight and obesity and their associated factors among early adolescence school children in urban and rural Portugal. BMC Nutr. 2017; 3.

6. World Health Organisation. Obesity And Overweight. https://www.who.int/dietphysicalactivity/media/en/gsfs_obesity.pdf. Accessed 18 May 2020.

7. GutieÂrrez-Fisac JL, Banegas JR, RodrõÂguez Artalejo F, Regidor. Increasing prevalence of overweight and obesity among Spanish adults, 1987-1997. International Journal of Obesity. 2000;24:1677-82.

8. World Health Organisation. Obesity and overweight. http://www.who.int/mediacentre/factsheets/fs311/en/. Accessed 4 February 2015.

9. Kelly T, Yang W, Chen CS, Reynolds K, He J. Global burden of obesity in 2005 and projections to 2030. International Journal of Obesity. 2008;32:1431-7.

10. The Economist Intelligence Unit Limited. Tackling obesity in ASEAN: Prevalence, impact, and guidance on interventions. 2017.

11. Ghee LK. A Review of Adult Obesity Research in Malaysia. Med J Malaysia. 2016;71:1-19.

12. World Health Organisation. Noncommunicable Disease Country Profile. http://whqlibdoc.who.int/publications/2011. Accessed 4 February 2015.

13. Nazaimoon WM, Kamarul IM, Amir S, Aziz SI, Ikram SI, et al. Prevalence of overweight and obesity among adult Malaysians: an update. Asia Pac J Clin Nutr. 2011;20:35-41.

14. Institute for Public Health (IPH). The Third National Health and Morbidity Survey 2006, Nutritional Status. Kuala Lumpur: Ministry of Health Malaysia; 2006.

15. Institute for Public Health (IPH). National Health and Morbidity Survey 2011 Vol. II: NonCommunicable Diseases. Kuala Lumpur: Ministry of Health Malaysia; 2011.

16. Institute for Public Health (IPH). National Health and Morbidity Survey 2015 Vol. II: NonCommunicable Diseases, Risk Factors \& Other Health Problems. Kuala Lumpur: Ministry of Health Malaysia; 2015.

17. Institute for Public Health (IPH). National Health and Morbidity Survey 2019: Non-communicable diseases, healthcare demand, and health literacy. Kuala Lumpur: Ministry of Health Malaysia; 2020.

18. Centers for Disease Control and Prevention. Adult Overweight and Obesity: Causes and Consequences. Atlanta: U.S. Department of Health and Human Services; 2012.

19. Wang YC, McPherson K, Marsh T, Gortmaker SL, Brown M. Health and economic burden of the projected obesity trends in the USA and the UK. The Lancet. 2011; 378. 
20. Withrow D, Alter DA. The economic burden of obesity worldwide: a systematic review of the direct costs of obesity. Obes Rev. 2011;12:131-41.

21. McKinsey Global Institute (MGI). Overcoming obesity: An initial economic analysis. 2014. Discussion paper.

22. Schoepp TN. Obesity in Malaysia. Unhealthy Eating is as Harmful as Smoking. Penang Institute Issues; 2017.

23. Plourde G, Prud'homme D. Managing obesity in adults in primary care. Cmaj. 2012;184:1039-44.

24. Ruelaz AR, Pamela D, Simon B, Andy L, David A, et al. Perceived Barriers to Weight Management in Primary Care-Perspectives of Patients and Providers. Society of General Internal Medicine. 2007;22:518-22.

25. Fu T, Lin Y, Huang C. Willingness to pay for obesity prevention. Economics Human Biology. 2011;9:316-24.

26. Puteh SEW, Ahmad SNA, Aizuddin AN, et al. Patients' willingness to pay for their drugs in primary care clinics in an urbanized setting in Malaysia: a guide on drug charges implementation. Asia Pac Fam Med. 2017;16:1-8.

27. Department of Statistics Malaysia. Sarawak@a Glance. https://www.dosm.gov.my/v1/index.php? $r=$ column/cone\&menu_id=clJnWTITbWFHdmUwbmtSTE1EQStFZz09. Accessed 20 May 2020.

28. Forest Department Sarawak. Types and Categories of Sarawak's Forest. https://forestry.sarawak.gov.my/page-0-160-593-Types-and-Categories-of-Sarawak-s-Forests.html. Accessed 20 May 2020.

29. Sarawak State Health Department.

Heritage in Health: The Story of Medical and Health Care Services in Sarawak (First; Sarawak State Health Department. Heritage in Health: The Story of Medical and Health Care Services in Sarawak (First;: Gracia TT. S. K. Yao, Kiyu A. S. C. Yao, Ong F, Z. Tambi, \& J. Adit, Eds.). Kuching, Sarawak: Sarawak State Health Department; 2012.

30. Sarawak State Health Department. Fasiliti Kesihatan Jabatan Kesihatan Negeri Sarawak. http://jknsarawak.moh.gov.my/v2/bm/business-directory/. Accessed 20 May 2020.

31. Ministry of Health Malaysia. Flying doctor service improves accessibility to healthcare in remote areas of Sarawak. https://kpkesihatan.com/2014/09/25/flying-doctor-service-improves-accessibilityto-healthcare-in-rural-sarawak/. Accessed 20 May 2020.

32. Sarawak State Health Department. Fasiliti Kesihatan Jabatan Kesihatan Negeri Sarawak. http://jknsarawak.moh.gov.my/v2/bm/business-directory/. Accessed 21 May 2020.

33. Bahagian Pembangunan Kesihatan Keluarga, Kementerian Kesihatan Malaysia. Sektor Perkembangan Infrastruktur Primer. http://fh.moh.gov.my/v3/index.php/tahap-perkhidmatan. Accessed 21 May 2020.

34. Ministry of Health Malaysia. NHMS: National Health \& Morbidity Survey 2015: Healthcare Demand. Ministry of Health Malaysia; 2015. 
35. BPPK. Sejarah. http://fh.moh.gov.my/v3/index.php/info-korporat/sejarah. Accessed 14 January 2020.

36. BPPK. Klinik Bergerak 1Malaysia. http://fh.moh.gov.my/v3/index.php/48-direktori/153-direktoriklinik-bergerak-1 malaysia. Accessed 14 January 2020.

37. New Straits Time. 1Malaysia Clinic to be rebranded as Community Clinic. 2018.

https://www.nst.com.my/news/nation/2018/06/384746/1 malaysia-clinic-be-rebranded-communityclinic-health-minister. Accessed 14 January 2020.

38. Ministry of Health Malaysia. National Health and Morbidity Survey 2015. Ministry of Health Malaysia; 2016.

39. Ministry Of Health Malaysia. Medium Term Strategic Plan To Further Strengthen The Cardiovascular Disease \& Diabetes Prevention \& Control Program In Malaysia (2010-2014): National Strategic Plan For Non Communicable Disease (NSPNCD). Ministry Of Health Malaysia; 2010.

40. Zhou Y, Hall AG. The Financial Burden of Overweight and Obesity among Elderly Americans: The Dynamics of Weight, Longevity, and Health Care Cost. HSR: Health Services Research. 2008;43:84968.

41. Hoomans T, Severens JL. Economic evaluation of implementation strategies in health care. Implementation Sci. 2014;9:168.

42. Donaldson C. Willingness to Pay and Publicly Funded Health Care: Contradiction in Terms? Glasglow: Office of Health Economic; 2011. In Seminar Briefing (pp. 1-18).

43. Goodacre S, McCabe C. An introduction to economic evaluation. Emerg Med J. 2001;19:198-201. 